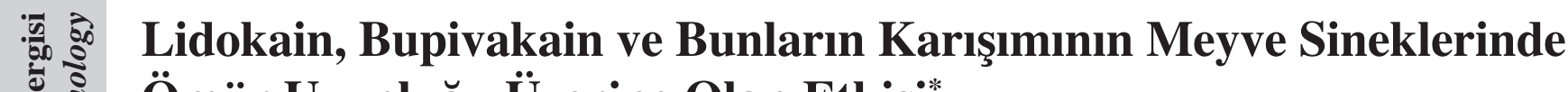 Ömür Uzunluğu Üzerine Olan Etkisi*
}

\author{
Hakan AŞKIN ${ }^{1}$, Ümmügülsün TÜKENMEZ ${ }^{2}$
}

ÖZET: Bu çalışmada, farklı özelliklere sahip iki anestezik maddenin Drosophila melanogaster'de (meyve sineği) ömür uzunluğu üzerine etkileri araştırılmıştır. Bu canlıda lokal anestezik maddelerin etkilerine yönelik oldukça az sayıda çalışma mevcuttur. Bu amaçla üçüncü evre larvalara lokal anestezik maddelerin farklı dozları (\% 0.0625, $\% 0.125, \% 0.25$ ve $\% 0.5)$ uygulanmıştır. Kontrol ve uygulama gruplarından elde edilen verilerdebu maddelere maruz kalan larvalardan gelişen ergin sineklerin ömür uzunluğueğişikliklerine neden olduğu belirlenmiştir. $\mathrm{Bu}$ çalışmadan elde edilen sonuçlar lidokain ve bupivakain uygulamalarının dişi bireylerde ömür uzunluğunu kontrole göre arttırdı̆̆ını ortaya çıkarmıştır $(\mathrm{p}<0.05)$. Bu iki lokal anestezik maddenin karışımı ise ortalama ömür uzunluğu ve maksimum ortalama ömür uzunluğu üzerine olumlu etki göstermemiştir.

Anahtar Kelimeler: Bupivakain, Drosophila melanogaster, lidokain, ömür uzunluğu.

\section{The Effect of Lidocaine, Bupivacaine and Their Mixture on the Life-span of Fruit Flies}

\begin{abstract}
In this study, the effects of two anesthetic agents with different properties on the life span of Drosophila melanogaster (fruit-fly) were investigated. There are very few studies on the effects of local anesthetics in this organism. For this purpose, different doses of the local anesthetic agents $(0.0625 \%, 0.125 \%, 0.25 \%$ and $0.5 \%$ ) were applied to third stage larvae. The data obtained from control and test groups showed that there were changes in the longevity of adults flies which grew from larvae to exposed to these agents. The present results elucidated that although lidocaine and bupivacaine applications increased life span in parallel with an increase in dose in female individuals compared to control $(\mathrm{p}<0.05)$. The mixture of these two local anesthetics affected adversely mean life span, maximum mean life span.
\end{abstract}

Keywords: Bupivacaine, Drosophila melanogaster, lidocaine, the life span.

\footnotetext{
Hakan Askin (0000-0003-3248-759X), Atatürk Üniversitesi, Fen Fakültesi Moleküler Biyoloji ve Genetik Bölümü, Erzurum, Türkiye Ummugulsum Tukenmez (0000-0002-3224-1920), Gazi Üniversitesi, Fen Fakültesi, Biyoloji Bölümü, Ankara Türkiye Sorumlu yazar/Corresponding Author: Hakan AŞKIN, haskin@atauni.edu.tr

Bu çalışma Ümmügülsüm Tükenmez'in Yüksek Lisans tezinin bir bölümüdür. Makale 3-7 Eylül 2012 tarihinde İzmir'de düzenlenen 21. Ulusal Biyoloji Kongresinde poster olarak sunulmuştur.
} 


\section{GíRiş}

Yaşlanma, çevresel faktörlerin etkisiyle canlı üzerinde yapısal ve işlevsel değişmelere yol açarak organizmayı ölüme götüren olaylar toplamı olarak tanımlanabilir (Cankurtaran, 2010). Bugünkü bilgiler yaşlanmanın dinamik ve şekillendirilebilir bir süreç olduğunu, gelişme ve yaşlanma süresinin sadece genlerle değil aynı zamanda çevresel ve epigenetik etkilerle kontrol edildiğini göstermektedir (Helfand ve Inouye, 2002; Plantamp ve ark., 2017). Canlıların ömür uzunluklarının çevresel faktörlerden etkilendiği (Parsons ve ark., 1973) ve stres faktörlerine karş1 direncin artmasının popülasyonun yaşlanma sürecini uzattığı bilinmektedir (Bourg ve ark., 2001). Yaşlanma, oldukça karmaşık bir olay olduğundan yaşlanmanın temel özelliklerini açıklamak için tek bir mekanizmanın varlığı yeterli değildir (Nalbant, 2006).

Halk arasında meyve sineği veya sirke sineği olarak bilinen Drosophila melanogaster, yaşlanma genetiği çalışmalarında en çok kullanılan model organizmalardan birisidir (Plantampa ve ark., 2017). Drosophila'da ömür uzunluğunu etkileyen birçok faktör bulunmaktadır. Bu faktörleri iç ve dış faktörler olarak iki büyük gruba ayırmak mümkündür. İç faktör olarak anasal yaş, yumurta üretimi, genetik yapı ve eşey tipi farklılığ $\breve{1}_{1}$ sayılabilir. Dış faktörler ise beslenme, radyasyon, popülasyon yoğunluğu, sıcaklık ve 1şık başlıkları altında toplanabilir (Altun, 2007; Altun ve ark., 2011) Dış faktörler arasında sayılan beslenme faktörü böceklerin ömür uzunluğunu önemli derecede etkilemektedir. Örneğin, kültür ortamına karbonhidrat kaynağı olarak sukroz yerine galaktoz konulduğunda Drosophila'ların ömür uzunlukları kısalmıştır (Jordens ve ark., 1999). Sadece sukroz+agar'la beslenen Drosophila subobscura popülasyonunun standart ortamda beslenenlerden yaklaşık \%50 daha kısa ortalama ömür uzunluğuna sahip oldukları bulunmuştur (Bozcuk, 1970). Bir liken türü olan Usnea longissima, D. melanogaster popülasyonlarında düşük konsantrasyonda ömür uzunluğunda artış, yüksek konsantrasyonda ise ömür uzunluğunda bir azalma göstermiştir (Altun, 2007). Başka bir çalışmada ise Porphyra (porphyran)'dan izole edilen polisakkaritlerin ömür uzunluğunu ve yaşam kabiliyetini arttırdı ğı belirlenmiştir (Zhao ve ark., 2008). Son yıllarda yapılan bazı çalışmalarda da beslenmenin Drosophila üzerindeki etkileri çalışılmıştır. Örneğin, dünya üzerinde nadir olarak bulunan Cerium elementinin Drosophila'da ortalama ömür uzunluğu, maksimum ömür uzunluğu ve fertilite üzerine etkileri incelenmiş ve Seryum'un artan konsantrasyonlarının her üç parametre içinde olumsuz etkileri rapor edilmiştir (Huang ve ark., 2010). Özellikle soya ve ürünlerinde bol miktarda bulunan ve östrojenik aktivitesinden dolayı alternatif tıpta da yaygın birşekilde kullanılmakta olan genistein D. melanogaster'de artan konsantrasyonlarda ömür uzunluğunu önemli ölçüde azaltmıştır (Altun ve ark., 2011). Beslenme yoluyla $D$. melanogaster'e anestezik maddelerinin ilk uygulamas1 2009 yılında gerçekleşmiştir. Bu çalışmada lidokain, prilonest ve septanest isimli anestezik maddelerin bir in vivo test sistemi olan somatik mutasyon ve rekombinasyon testi (SMART) ile genotoksisiteleri araştırılmıştır (Schneider ve ark., 2009). Araştırma sonucunda yalnızca prilonestin somatik hücrelerde genotoksik aktivite sergilediği, lidokain ve septanestin ise herhangi bir gen veya kromozomal mutasyona yol açmadı $\breve{g ̆}_{1}$ bildirilmiştir.

Lokal anestezik maddeler, uygun dozlarda verildiklerinde uygulama yerinde sinir iletimini geçici olarak bloke eden maddelerdir. Günümüzde çok sayıda lokal anestezik geliştirilerek hekimliğin hizmetine sunulmuştur. Bunlar kokain, prokain, tetrakain, tutakain, butakain ester, lidokain, prilokain, bupivakain, mepivakain amid, fenokain ve dipiridon gibi çok sayıda olup anestezik amaçla kullanılmaktadır (Doğan, 1999).

Amid grubu bir lokal anestezik olan lidokain (xylocaine, lignocaine, 1948), klinik uygulamalarda ilk kullanılan maddedir (Şekil 1). Etki gücünün fazlalığı, etki sürecinin hızlı olması ve yeteri kadar etkisinin sürmesi nedenleriyle en sık kullanılan lokal anesteziklerden birisidir (Ragab ve Fathy, 2018). Yaygın kullanımından dolayı doz aşımı vakalarına sıklıkla rastlanabilir ve sistemik intoksikasyona neden olabilirler. $\mathrm{Bu}$ durumlarda merkezi sinir sisteminde (MSS) ve kardiyovasküler sistemde toksisite gözlenebilir (Çelik ve ark., 2008).

Amid grubu bir başka lokal anestezik olan bupivakain (marcaine, carbostesin, sensorcaine, 1963), (Şekil 2), cilt altına, periferik sinir bloklarına, 
epidural ve spinal anestezi şeklinde uygulanmaktadır (Kayhan, 1997). Bupivakain lokal anestezik ajanlar içinde yan etkileri en iyi bilinen, uzun etki süreli ve kardiyovasküler toksisitesi en fazla olan lokal anesteziktir (Rachel ve Markham, 2000). Yüksek doz uygulandığında hipotansiyona, miyokard depresyonuna, dilde uyuşmaya, sersemlik haline, baş dönmesine, bulanık görmeye, tremor ve bunları takip eden uyku haline, bilinç kaybına ve solunum durması gibi yan etkilere sahip olduğu bildirilmiştir (Mycek ve ark., 1998; Angerame ve ark., 2018).

\section{MATERYAL VE YÖNTEM}

\section{Kullanılan Organizma ve Yaşam Koşulları}

Deneylerimizde kullandığımız organizma dişi Oregon R soyu Drosophila melanogaster (Drosophila erkeklerinde rekombinasyon görülmez) böceklerin
Diptera takımı, Drosophilidae familyasına aittir. Yabanıl tiplerde kahverengi-gri vücut rengi, yuvarlak kırmızı göz ve uzun kanat fenotipi gözlenir (Uysal ve ark., 2006). Deneyde kullanılan bütün stok kültürler ve kurulan deney sistemleri $25 \pm 1^{\circ} \mathrm{C}$ sicaklık ve \%4060 bağ 11 nem içeren ortamlarda ve sürekli karanlık koşullarda Atatürk Üniversitesi Fen Fakültesi Biyoloji Bölümü'nde Genetik Araştırma Laboratuarı'nda tutuldu. Çalışmalar sırasında sinekler sadece çaprazlama, aktarma, virjin toplama ve larva toplama işlemleri için aydınlık ortama alındı.

\section{Kimyasal Bileşikler}

Lidokain [CAS No. 137-58-6, Jetmonal ${ }^{\circledR}$ (lidokain HCI $\% 2.20 \mathrm{mg} / \mathrm{ml} \mathrm{NaCI} 4.6 \mathrm{mg} / \mathrm{ml})$ ] ve Bupivakain [CAS No. 18010-40-7, Marcaine ${ }^{\circledR} \quad$ (Bupivakain $^{-}$ HCI $\% 0.5,5 \mathrm{mg} / \mathrm{ml} \mathrm{NaCI} 8 \mathrm{mg} / \mathrm{ml}$ )] maddeleri Atatürk Üniversitesi, Tip Fakültesi, Anesteziyoloji Bölümü'nden temin edildi.

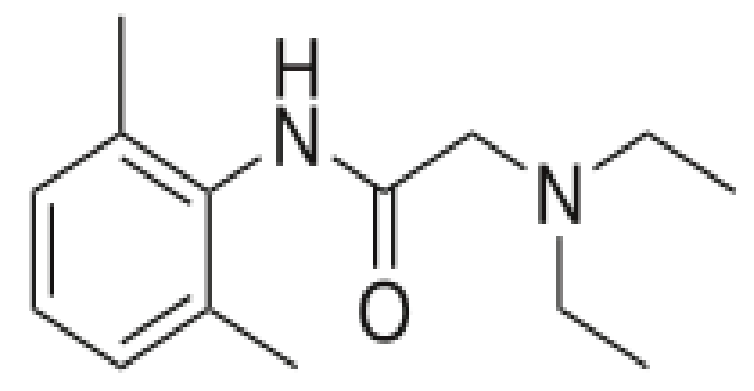

Şekil 1. Lidokainin kimyasal yapısı

Instant Drosophila besiyeri Sigma ${ }^{\circledR}$ Şirketinden satın alındı. LIDO ve BUPI bileşikleri \% 0.9 NaCI içeren fizyolojik su ile seyreltildi.

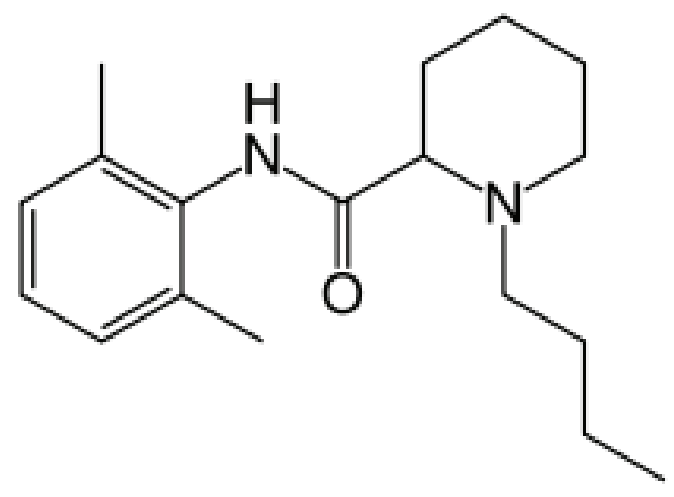

Şekil 2. Bupivakainin kimyasal yapısı 
Bu lokal anestezikler ve karışımları dört farklı konsantrasyonda (\% $0.0625 ; \% 0.125 ; \% 0.25 ; \% 0.5)$ test edildi (Schneider ve ark., 2009). Hazırlanan tüm konsantrasyonlar Çizelge 1'de gösterilmiştir.

Çizelge 1. Bu çalışma için kullanılan farklı besi ortamlarının içeriği

\begin{tabular}{|l|c|c|}
\hline & \multicolumn{2}{|c|}{ Besi ortam içerikleri } \\
\hline Besiyeri No & LIDO $(\%)$ & -- \\
\hline Kontrol $(\% 0.9 \mathrm{NaCl})$ & -- & -- \\
\hline LIDO I & 0.0625 & -- \\
\hline LIDO II & 0.125 & 0.0625 \\
\hline LIDO III & 0.25 & 0.125 \\
\hline LIDO IV & 0.5 & 0.25 \\
\hline BUPI I & -- & 0.5 \\
\hline BUPI II & -- & 0.0625 \\
\hline BUPI III & -- & 0.125 \\
\hline BUPI IV & -- & 0.25 \\
\hline LIDO I + BUPI I & 0.0625 & 0.5 \\
\hline LIDO II + BUPI II & 0125 & - \\
\hline LIDO III + BUPI III & 0.25 & - \\
\hline LIDO IV + BUPI IV & 0.5 & - \\
\hline
\end{tabular}

$72 \pm 4$ Saatlik (üçüncü evre) Larvalara LİDO ve BUPI'nin Uygulanması

Aynı yaşta sinekler elde etmek için ergin sinekler 25'erli gruplar halinde Standart Drosophila Besiyeri (SDB) içeren şişelere alındı. Yaklaşık olarak 9-10 gün sonra yeni bireyler elde edildi. Virgin dişiler ve yeni nesil erkekler SDB içeren şişelerde ayrı ayrı toplandı. Daha sonra bu sinekler besiyerlerinde ayrı gruplar halinde çaprazlandi.

Virgin dişilerle erkeklerin çaprazlanmasıyla elde edilen yumurtalar bira mayası ile zenginleştirilmiş standart bir ortamda 8 saat süreyle toplandı (Graf ve Van Schaik 1992). Standart çaprazlamadan elde edilen üiç günlük larvalar 9'ar ml test solüsyonları ile sulandırılmış 4.5 g kuru Instant Drosophila Medium (IDM) içeren şişelere aktarıldı.

Larvalar gelişimlerinin geri kalan kısmı için bu ortamda beslendiler (yaklaşık olarak 48 saat). Hayatta kalan larvaların pupa evresine geçişi ile beslenme sonlandı. Her bileşik ile üç deney yapıldı. Larvalar test bileşiklerinin farklı konsantrasyonları ile beslendi. Ayrica, \% 0.9'luk fizyolojik su kontrol olarak $72 \pm 4$ saatlik larvalara aynı şekilde uygulandı.

\section{Ömür Uzunluğu Çalışmaları}

Test bileşenlerinin larvalara uygulanmasına müteakip pupadan yeni çıkan bireyler eter ile bayıltılarak dişi sinekler ayrılarak standart IDM içeren dört kültür şişesinin her birine 25'er adet (toplam 100 sinek) dişi sinek konuldu. Böylece sinekler hemen hemen aynı yaşta oldular. Sineklerin sayısı her sabah ve her akşam kontrol edildi ve ölü sineklerin sayısı kayıt edilerek besiyerlerinden uzaklaştırıldı. Besi ortamları her üç günde bir yenilendi. Uygulama son birey ölünce sonlandırıldı. Ortalama ömür uzunluğu (=Mean Life Span: MLS) hayatta kalan sineklerin sayısı \% 50'ye ulaştı ğı gün olarak, maksimum ortalama ömür uzunluğu (Maximum Mean Life Span: MMLS) ise yine hayatta kalan sineklerin sayısı \% 10'a ulaştığ gün olarak belirlendi (Huang ve ark., 2010).

\section{İstatistik Analizler}

Kontrol ve uygulama gruplarının ortalama ömür uzunluğu değerlerini karşılaştırmak için tek yönlü varyans analizi ve Duncan'ın çoklu karşlaş̧tırma testi kullanılmıştır. İstatistiksel değerlendirmelerde $\mathrm{p}<0.05$ değeri dikkate alınmıştır. Bunun için SPSS (SPSS INC., USA) 16 programı kullanılmıştır. 


\section{BULGULAR VE TARTIŞMA}

Buçalışmada lidokain, bupivakain ve karışımlarının farklı konsantrasyonlarının D. melanogaster'de ömür uzunluğu üzerine etkileri incelenmiştir.

\section{LIDO’nun Ömür Uzunluğu Üzerine Etkisi}

Deneylerimizde kullandığımız lidokain dişi sineklerde ortalama ömür uzunluğunu (MLS) konsantrasyon farklılığına göre değişik şekillerde etkilemiştir. Sonuçlar Çizelge 2'de gösterilmiştir.
LIDO III ve LİDO IV (yüksek konsantrasyonlar) uygulama gruplarımızda MLS değerleri sırasıyla 49 ve 53 gün olarak belirlenmiştir. $\mathrm{Bu}$ değerler kontrol grubuyla (44) kıyaslandığında MLS'de önemli bir artış gözlenmiştir $(\mathrm{p}<0.05)$. Benzer bulgular maksimum ortalama yaşamda da (MMLS) görülmüsştür. Kontrol grubu dişilerde maksimum ortalama ömür uzunluğu 57 gün olurken bu değer lidokain uygulamasının en yüksek dozu olan \% 0.5 için 61 gün olarak tespit edilmiştir (Çizelge 2).

Çizelge 2. Farklı LIDO konsantrasyonları ile beslenen D. melanogaster dişi bireylerinin ömür uzunluğundaki değişim

\begin{tabular}{|c|c|c|c|}
\hline $\begin{array}{c}\text { Lidokain } \\
\text { konsantrasyonu (\%) }\end{array}$ & $\begin{array}{c}\text { Sineklerin } \\
\text { sayısı }\end{array}$ & $\begin{array}{c}\text { Ortalama ömür uzunluğu } \\
(\text { MLS) } \pm \text { SD }\end{array}$ & $\begin{array}{c}\text { Maksimum ortalama ömür } \\
\text { uzunluğu (MMLS) } \pm \text { SD }\end{array}$ \\
\hline & Dişi & Dişi & $57.33 \pm 4.72^{\mathrm{a}}$ \\
\hline 0 (Kontrol) & 100 & $44.33 \pm 2.08^{\mathrm{a}}$ & $55.33 \pm 3.51^{\mathrm{a}}$ \\
\hline LIDO I (0.0625) & 100 & $42.33 \pm 2.89^{\mathrm{a}}$ & $56.00 \pm 2.00^{\mathrm{a}}$ \\
\hline LIDO II (0.125) & 100 & $43.00 \pm 2.8^{\mathrm{a}}$ & $58.33 \pm 2.52^{\mathrm{a}}$ \\
\hline LIDO III (0.25) & 100 & $49.33 \pm 4.16^{\mathrm{b}}$ & $61.33 \pm 2.51^{\mathrm{a}}$ \\
\hline LIDO IV (0.5) & 100 & $53.33 \pm 2.08^{\mathrm{b}}$ & \\
\hline
\end{tabular}

*Farklı harflerle gösterilen gruplar arasındaki fark ömür uzunluğu için önemlidir $(\mathrm{p}<0.05)$

\section{BUPI'nin Ömür Uzunluğu Üzerine Etkisi}

Deneylerimizde kullandığımız ikinci madde olan bupivakainin dişi MLS üzerine etkisi incelendiğinde; en düşük doz olan BUPI I'de MLS değeri, kontrol grubunun MLS değerine (44) göre azalmıştır $(\mathrm{p}<0.05)$. Diğer dozlarda ise konsantrasyon artışına göre MLS değerinde belirgin bir artış gözlenmiştir. Sonuçlar
Çizelge 3'de görülmektedir. BUPI' nin dişi bireylerin MMLS'ye etkisi MLS ile farklılık göstermiştir.

Kontrol grubunun MMLS değeri 57 gün iken; BUPI I ve BUPİ II' de kontrole göre düşüş gözlenmiştir. Uygulama grupları ile kontrol grubu arasında belirgin bir fark gözlenmemiştir $(\mathrm{p}<0.05)$.

Çizelge 3. Farklı BUPİ konsantrasyonları ile beslenen D. melanogaster dişi bireylerinin ömür uzunluğundaki değişim

\begin{tabular}{|c|c|c|c|}
\hline $\begin{array}{c}\text { Bupivakain } \\
\text { konsantrasyonu }(\%)\end{array}$ & $\begin{array}{c}\text { Sineklerin } \\
\text { sayısı }\end{array}$ & $\begin{array}{c}\text { Ortalama ömür uzunluğu } \\
(\mathbf{M L S}) \pm \text { SD }\end{array}$ & $\begin{array}{c}\text { Maksimum ortalama ömür } \\
\text { uzunluğu (MMLS) } \mathbf{\text { SDD }}\end{array}$ \\
\hline & Dişi & Dişi & Dişi \\
\hline 0 (Kontrol) & 100 & $44.33 \pm 2.08^{\mathrm{a}, \mathrm{b}}$ & $57.33 \pm 4.72^{\mathrm{a}}$ \\
\hline BUPI I & 100 & $40.33 \pm 2.89^{\mathrm{a}}$ & $53.33 \pm 2.08^{\mathrm{a}}$ \\
\hline BUPI II & 100 & $47.00 \pm 3.00^{\mathrm{b}}$ & $54.33 \pm 3.05^{\mathrm{a}}$ \\
\hline BUPI III & 100 & $49.67 \pm 3.51^{\mathrm{b}, \mathrm{c}}$ & $57.67 \pm 4.04^{\mathrm{a}}$ \\
\hline BUPI IV & 100 & $53.67 \pm 3.78^{\mathrm{c}}$ & $56.33 \pm 2.52^{\mathrm{a}}$ \\
\hline
\end{tabular}

*Farklı harflerle gösterilen gruplar arasındaki fark ömür uzunluğu için önemlidir $(\mathrm{p}<0.05)$ 


\section{LiDO + BUPI'nin Ömür Uzunluğu Üzerine Etkisi}

Deneylerimizde son olarak LIDO ve BUPİ karışımının ömür uzunluğu üzerindeki etkileri incelenmiştir (çizelge 1). Bu karışımın dişi bireylerdeki MLS'ye etkileri incelendiğinde kontrol grubunun MLS değerinin 44 gün olduğu gözlenmiştir. İlk uygulama grubunun (LIDO I + BUPİ I) MLS değerinde kontrol grubuna göre düşüş gözlenmiştir. İkinci uygulama (LIDO II + BUPİ II) dişi bireylerde MLS değerini diğer gruplara göre belirgin bir şekilde artırmıştır. Üçüncü uygulama (LIDO III + BUPI III) grubunun MLS değerinin kontrol grubu ile aynı olduğu gözlenmiştir. En yüksek konsantrasyonda ise (LIDO IV + BUPİ IV) ise MLS değerini kontrol grubuna göre artırmıştır; ancak en olumlu etki ikinci uygulama grubunda (LIDO $\% 0.125$ + BUPİ \% 0.125) gözlenmiştir. Ayrıca bu karışımın dişi bireylerdeki MMLS değerine etkisi incelendiğinde ise etkinin yine benzer şekilde olduğu görülmüsşür. MMLS'yi en olumlu etkileyen uygulama grubu LIDO II + BUPI II (\% $0.125+\%$ 0.125) dir. Diğer uygulama gruplarında ise kontrol grubuna göre azalış gözlenmiştir. Sonuçlar Çizelge 4'te görülmektedir $(\mathrm{p}<0.05)$.

Çizelge 4. Farklı LİDO + BUPİ konsantrasyonları ile beslenen D. melanogaster dişi bireylerinin ömür uzunluğundaki değişim

\begin{tabular}{|c|c|c|c|}
\hline $\begin{array}{c}\text { LIDO+BUPI } \\
\text { konsantrasyonu (\%) }\end{array}$ & $\begin{array}{c}\text { Sineklerin } \\
\text { sayısı }\end{array}$ & $\begin{array}{c}\text { Ortalama ömür uzunluğu } \\
\text { (MLS) } \pm \text { SD }\end{array}$ & $\begin{array}{c}\text { Maksimum ortalama ömür } \\
\text { uzunluğu (MMLS) } \pm \text { SD }\end{array}$ \\
\hline Dişi & 100 & Dişi & Dişi \\
\hline LIDO I+BUPI I & 100 & $44.33 \pm 2.08^{\mathrm{a}}$ & $57.33 \pm 4.72^{\mathrm{a}}$ \\
\hline LIDO II+BUPI II & 100 & $53.00 \pm 3.00^{\mathrm{a}}$ & $53.00 \pm 3.00^{\mathrm{a}}$ \\
\hline LIDO III+BUPI III & 100 & $44.00 \pm 4.00^{\mathrm{a}} \pm 2.52^{\mathrm{a}}$ \\
\hline LIDO IV+BUPI IV & 100 & $47.33 \pm 5.51^{\mathrm{a}, \mathrm{b}}$ & $54.67 \pm 3.51^{\mathrm{a}}$ \\
\hline
\end{tabular}

* Farklı harflerle gösterilen gruplar arasındaki fark ömür uzunluğu için önemlidir (p<0.05)

Lokal anestezik maddelerin dişi Drosophila BUPI ve MIX için sırasıyla Şekil 3, Şekil 4 ve Şekil melanogaster' in yaşam yüzdesi üzerine etkileri LIDO, 5'te gösterilmiştir.

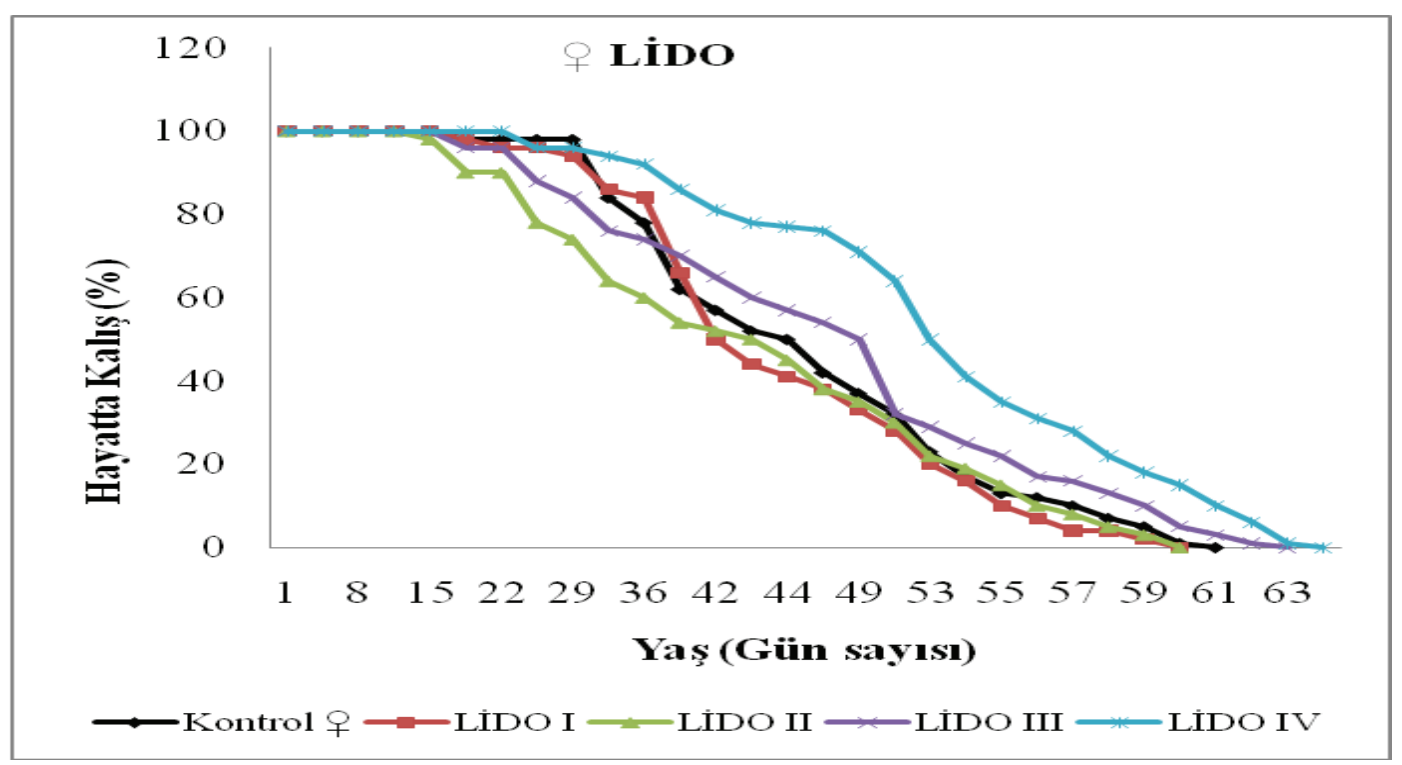

Şekil.3. LIDO’nun dişi bireylerde ömür uzunluğuna etkisi 


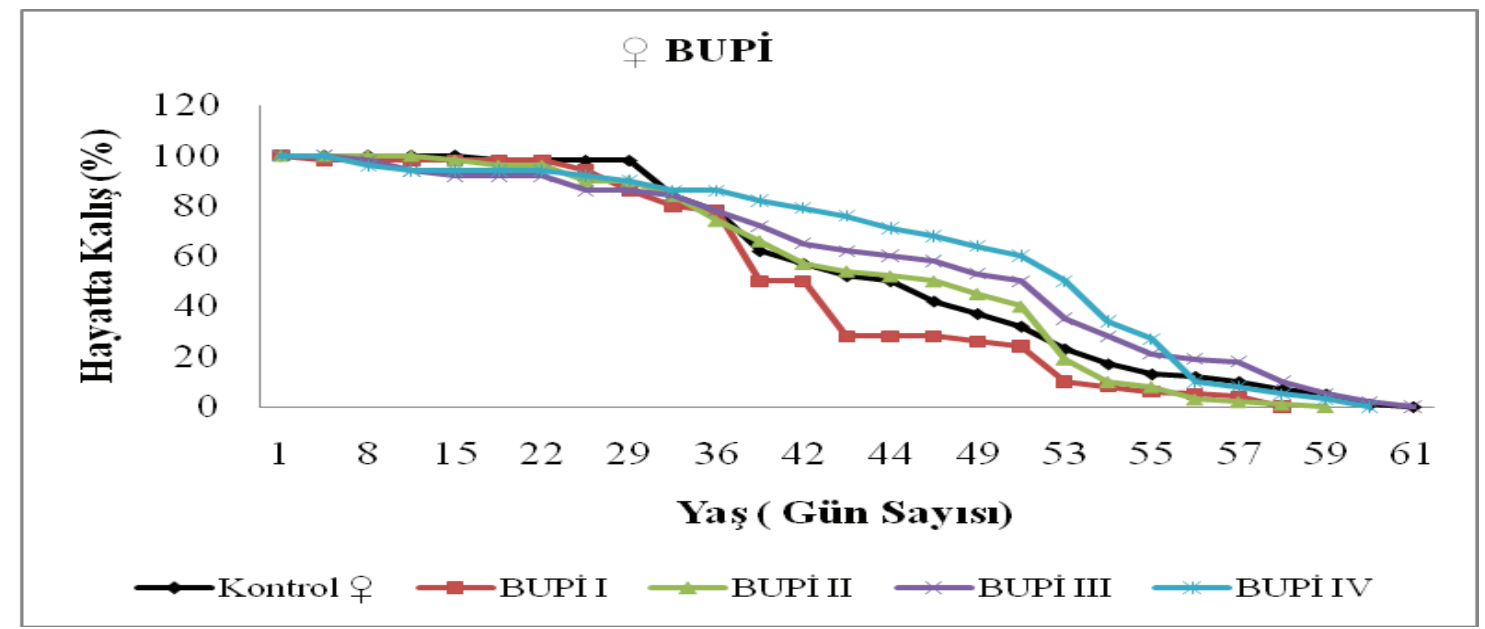

Şekil.4. BUPİ' nin dişi bireylerde ömür uzunluğuna etkisi

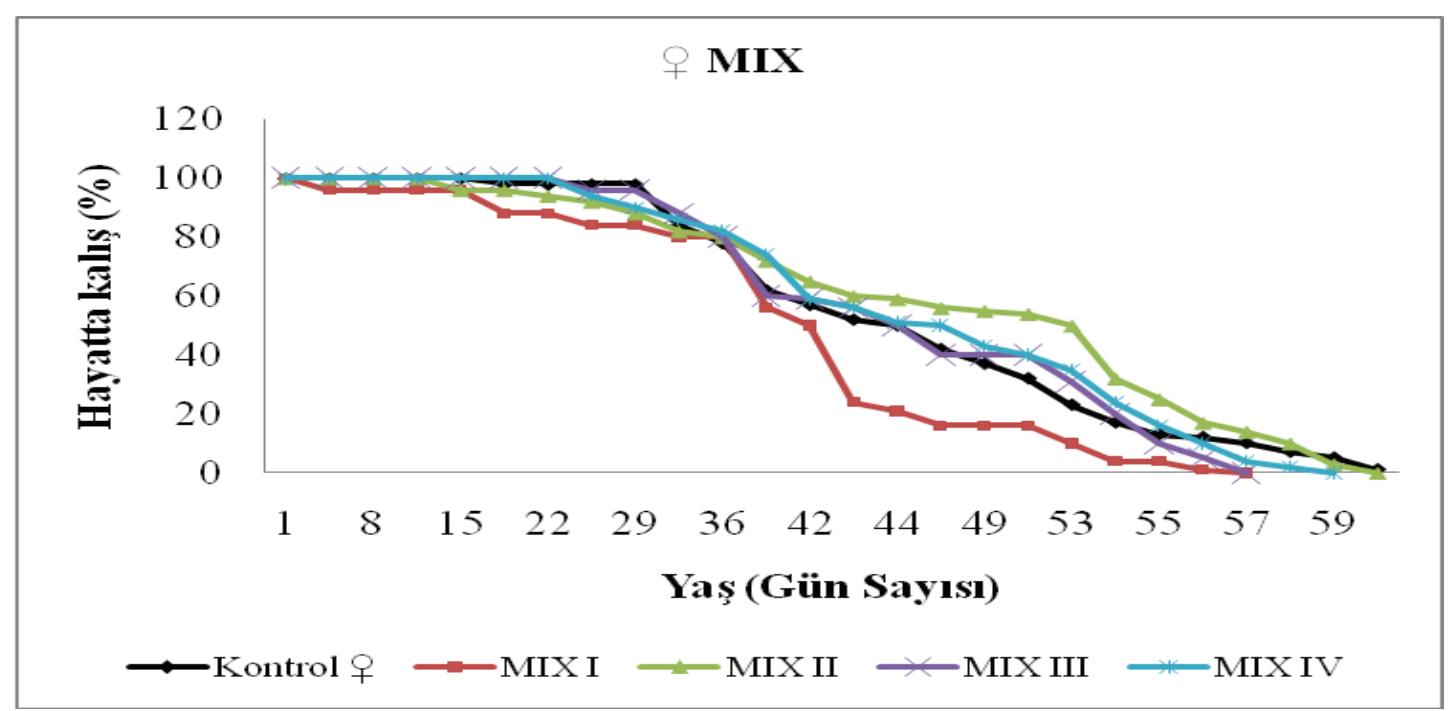

Şekil 5. LIDO + BUPİ’ nin dişi bireylerde ömür uzunluğuna etkisi

Çalışmalarımız esnasında ömür uzunluğunu etkileyebilecek iç ve diş faktörler sabit tutulmuştur. $\mathrm{Bu}$ şekilde aynı şartlarda yetiştirilen aynı genotipe sahip bireylerin ömür uzunluklarındaki sapmalara besi ortamına ilave edilen anestezik maddelerin neden olduğu söylenebilir.

Yaptığımız literatür taramalarında, lidokain ve bupivakainin Drosophila melanogaster'in ömür uzunluğu üzerine etkisiyle ilgili sonuçlara rastlanmamıştır. $\mathrm{Bu}$ nedenle bulgularımız, farklı organizmalardaki anestezik maddelerin etkileri dikkate alınarak değerlendirilmiştir. Deneylerden elde ettiğimiz bulgular, bazı araştırmacılar tarafından çeşitli organizmalar üzerinde yapılan bazı çalışmaların sonuçlarıyla paralellik göstermektedir. Örneğin, lidokain, prilonest ve septanest isimli anestezik maddelerin Drosophila'da bir in vivo test sistemi olan somatik mutasyon ve rekombinasyon testi (SMART) ile genotoksisiteleri araştırılmışıtır (Schneider ve ark., 2009). Araştırma sonucunda yalnızca prilonestin somatik hücrelerde genotoksik aktivite sergilediğini, lidokain ve septanestin ise herhangi bir gen veya kromozomal mutasyona yol açmadı ̆̆ını bildirmişlerdir. Sprague Dawley sıçanlarında gebelik esnasında uygulanan lidokainin teratojenik ve toksikolojik etkilerini değerlendirmişlerdir. Yapılan çalışma sonucunda yüksek dozlarda dahi lidokain belirgin bir toksikolojik veya teratojenik etki yapmamıştır (Ramazzotto ve ark., 1985). 
Çalışmalarımızda kullandığımız lidokain ve bupivakainin de içinde bulunduğu anestezik maddelerin antioksidan gibi davranabildikleri birçok araştırıcı tarafından rapor edilmiştir (Lesnefsky ve ark., 1989; Günaydın, 2000; Lenfant ve ark., 2004).

Köpekler üzerinde yapılan bir çalışmada lidokainin, lipid peroksidasyon ürününün serbest bırakılmasını azaltarak miyokardiyal hücre zarını koruduğu bildirilmiştir (Lesnefsky ve ark., 1989). Bir başka çalışmada ise lidokain, bupivakain ve ropivakain lokal anestezik maddelerinin antioksidan potansiyelleri insan eritrosit hücrelerinde çalışılmıştır (Lenfant ve ark., 2004). In vitro olarak yapılan bu deneyde oksidatif strese maruz bırakılmış insan eritrosit hücre modelinde lidokainin antioksidan potansiyelinin fazla olduğu bildirilmiştir. $\mathrm{Bu}$ araştırıcılar, bu tür etkilerin mekanizmalarının tam olarak açık olmadığını ve hücre metabolizmasında, membran akışkanlığı ve polaritesinde veya iyon kanal sisteminde $\left(\mathrm{Na}^{+}, \mathrm{K}^{+}\right)$ meydana gelebilecek modifikasyonlar gibi çeşitli mekanizmaları içerebileceğini bildirmişlerdir. Dahası lokal anestezik ajanların antioksidan özellikleri kendilerinin doğallığına, fiziksel ve kimyasal özelliklerine veya güçlerine göre farklılık gösterebilir.

Bupivakainin antioksidan özelliklerinin belirlenmesi amacıyla insan lökosit hücrelerine uygulanmıştır (Günaydın ve Demiryürek, 2003). $\mathrm{Bu}$ çalışmanın sonucunda, bupivakainin süperoksit, $\mathrm{HOCl}$ (hipokloröz asit) ve peroksinitriti temizleyici (süpürücü) etki gösterdiğini bildirmişlerdir. Araştırıcılar bupivakainin lökositlerden salınan ekstraselüler enzimleri ve süperoksit üretimini önemli derecede azaltarak veya NADPH oksidaz enzimini inhibe ederek bu etkiyi gösterdiğini belirtmişlerdir. Bizim elde ettiğimiz sonuçların nedeni de bu sebepler olabilir.

2,2-azobisdihydrochloride ile oluşturulmuş serbest radikal artı̧̧ına karşı bupivakainin koruyucu bir etki sağladığı bildirilmiştir (Lenfant ve ark., 1999). Ayrıca bupivakainin rat karaciğer mikrozomlarının lipid peroksidasyonu üzerinde antioksidan özelliklere sahip olduğu rapor edilmiştir (De Iuliis ve ark., 2001).

Lidokain eritrositlerin şekillerini de değiştirerek eritrositlerin oksidasyona karşı direncini arttırabilir (Lenfant, 2004). Eğer eritrositlerin şekli değişirse yüzeyin serbest radikallere maruz kalması azalabilir. Ayrıca lidokain eritrosit membranı ile elektrostatik etkileşime girerek çift zarlı membran içine girebilir ve akışkanlığını değiştirebilir (Spinedi ve ark., 1989). Gerçekte, eğer lokal anestezikler membran akışkanlığını ve konformasyonunun değişimine neden olarak oksidatif strese karşı eritrositleri koruyabiliyorsa bu anestezik maddeler aynı etkiyi diğer hücreler içinde gösterebilirler. Klinik uygulamalarda bu özelliklerin etkilerini değerlendirmek için daha fazla araştırmaya gereksinim vardır. Diğer yandan bupivakainin de membran kutuplaşmasina neden olabilen membran stabilize edici özellikleri vardır (Seeman, 1972). $\mathrm{Bu}$ mekanizma oksidatif strese karşı bupivakainin koruyucu etkisi olarak düşünülebilir.

\section{SONUÇ}

Mevcut çalışmamızın sonuçları, tek başına kullanılan lidokain ve bupivakainin dişi bireylerde (LIDO I ve BUPİ I hariç) ömür uzunluğunu arttırdığını göstermiştir (Muhtemelen bu iki anestezik maddenin düşük dozları serbest radikal oluşumuna karşı koruma meydana getirmek için yetersiz kalmış olabilir). Bu iki lokal anestezik maddenin karışımı ise ömür uzunluğu üzerinde istatistiksel olarak önemli bir değişim göstermemiştir $(\mathrm{p}<0.05)$. Günümüzde özellikle lokal anestezik maddeler ile ilgili bu tür çalışmalar çok sınırlı düzeydedir. Bu konunun aydınlatılması için daha fazla çalışmanın yapılması gerekmektedir.

\section{KAYNAKLAR}

Altun D, 2007. Usnea longissima Ach. Likeninin Drosophila melanogaster' in Çeşitli Gelişim Parametreleri ve Ömür Uzunluğu Üzerine Etkileri, Atatürk Üniversitesi Fen Bilimleri Enstitüsü, Yüksek Lisans Tezi (Basılmış).

Altun D, Uysal H, Așkın H, Ayar A, 2011. Determination of the effects of genistein on the longevity of Drosophila melanogaster Meigen (Diptera; Drosophilidae). Bulletin of Environmental Contamination and Toxicology, 86 (1): 120123.

Angerame MR, Hart GP, Odum SM, Springer BD, 2018. Are reinfusion drains safe to use with periarticular liposomal bupivacaine? An analysis of systemic bupivacaine toxicity. Arthroplasty Today, 4: 227-231.

Bourg EL, Valenti P, Lucchetta P, Payer F, 2001. Effects of mild heat shocks at young age on aging and longevity in Drosophila melanogaster. Biogerontology, 2: 155-164.

Bozcuk AN, 1970. Molecular turnover and ageing in Drosophila subobscura. University of Sussex, Doctorate Thesis (Printed). 
Cankurtaran M, 2010. Yaşlılık, yaşlanma mekanizmaları, antiaging ve yaşam tarzı değişiklikleri. 7. Ulusal İç Hastalıkları Kongresi, 2000, Antalya.

Çelik M, Uysal SÖ, Şekerel BE, 2008. Lidokaine Bağlı Allerji veya Toksisite? Astım Allerji. İmmünoloji, 6 (1): 22-24.

De Iuliis A, Zanatta L, Vincenti E, Galzigna L, 2001. Differences of ropivacaine and bupivacaine relevant to anti-infl amatory activity platelet aggregation and anti oxidant activity in vitro. Farmacology, 56 (3): 153-157.

Doğan A, 1999. Farmakoloji ve Toksikoloji. Kafkas Üniversitesi Sağlık Yüksekokulu Yayınları No: 1, s.38-40, Kars-Türkiye.

Graf U, Van Schaik N, 1992. Improved high bioaktivation cross for the wing somatic mutation and recombiration test in Drosophila melanogaster. Mutation Research, 271: 59-67.

Günaydın B, 2000. Lokal Anesteziklerin Antioksidan Aktivitelerinin Kemiluminans Yöntemiyle Araştırılması, Gazi Üniversitesi Sağlık Bilimleri Enstitüsü, Doktora Tezi (Basılmış).

Günaydın B, Demiryürek AT, 2003. Effects of tetracaine and bupivacaine on chemiluminescence generated by formylmethionyl-leucyl-phenylalanine-stimulated human leukocytes and cell-free systems. International Immunopharmacology, 3: 757-764.

Helfand SL, Inouye SK, 2002. Rejuvenating views of the ageing process. Nature Reviews Genetics, 3: 149-153.

Huang SF, Li ZY, Wang XQ, Wang QX, Hu FF, 2010. Cerium caused life span shortening and oxidative stress resistance in Drosophila melanogaster. Ecotoxicology and Environmental Safety, 73: 89-93.

Jordens RG, Berry MD, Gillot C, Boulton AA, 1999. Prolongation of life in an experimental model of aging in Drosophila melanogaster. Neurochemical research, 24 (2): 227-233.

Kayhan Z, 1997. Klinik Anestezi. Logos Yayıncılık No: 2, s. 447, İstanbul-Türkiye.

Lenfant F, Lahet JJ, Courderot-Masuyer C, Freysz M, Rochette L, 2004. Lidocaine has better antioxidant potential than ropivacaine and bupivacaine: in vitro comparison in a model of human erythrocytes submitted to an oxidative stres. Biomedicine and Pharmacotherapy, 58: 248-254.

Lenfant F, Lahet JJ, Volot F, Schafer I, Freysz M, Rochette L, 1999. Effects of bupivacaine on human erythrocytes submitted to stresss and evidence for an interaction between bupivacaine and flumazenil. British Journal of Clinical Pharmacology, 48: 826-828.

Lesnefsky E, VanBenthuysen K, McMurtry L, Shikes RH, Johnston RB, Horwitz LD, 1989. Lidocaine reduces canine infarct size and decreases release of a lipid peroxidation product. Journal of Cardiovascular Pharmacology, 13: 895-901.
Mycek MJ, Harvey RA, Champe PC, 1998. Lippincott's Illustrated review: Pharmacology. Nobel Tip Kitapevleri No:2, s.117118, İstanbul-Türkiye.

Nalbant S, 2006. Yaşlanmanın Biyolojisi. Türkiye Fiziksel Tıp ve Rehabilitasyon Dergisi, 52 (A): 12-17.

Parsons PA, Roman HL, Sandler LM, Campell A, 1973. Annual Review of Genetics, Annual Review Inc, No: 7, 504 pp. California-United States of America.

Plantamp C, Estragnata V, Fellous S, Desouhanta E, Gibert P. 2017. Where and what to feed? Differential effects on fecundity and longevity in the invasive Drosophila suzukii. Basic and Applied Ecology, 19: 56-66.

Rachel H, Markham A, 2000. Levobupivacaine: A Review of its Pharmacology and Use as a Local Anaesthetic. Drugs, 59: 551-579.

Ragab GA, Fathy MZ, 2018. Evaluation of the epidural analgesic effect of Nalbuphine, Lidocaine and Nalbuphine-Lidocaine combination in bucks. Beni-Suef University Journal of Basic and Applied Sciences, 7: 27-30.

Ramazzotto LJ, Curro FA, Paterson JA, Tanner P, Coleman M, 1985. Toxicological assessment of lidocaine in the pregnant rat. Journal of Dental Research, 64 (10): 1214-1218.

Schneider LE, do Amaral VS, Dihl RR, Lehmann M, Reguly ML, de Andrade HHR, 2009. Assessment of genotoxicity of Lidocaine, Prilonest and Septanest in the Drosophila wingspot test. Food and Chemical Toxicology, 47: 205-208.

Seeman P, 1972. The membrane actions of anesthetics and tranquilizers. Pharmacological Reviews, 24: 583-655.

Spinedi A, Pacini L, Luly P, 1989. A study of the mechanism by which some amphiphilic drugs affect human erythrocyte acetylcholinesterase activity. Biochemichal Journal, 261: 56973.

Uysal H, Şişman T, Așkın H, 2006. Drosophila biyolojisi ve çaprazlama yöntemleri. Ataturk Üniversitesi Yayınları No:1, s.25, Erzurum-Türkiye.

Zhao T, Zhang Q, Qi H, Liu X, Li Z, 2008. Extension of life span and improvement of vitality of Drosophila melanogaster by long-term supplementation with different molecular weight polysaccharides from Porphyra haitanensis. Pharmacological Research, 57: 67-72. 